\title{
HEPATOPULMONARY SYNDROME: PROPOSED MEDIATORS OF PULMONARY VASODILATION
}

\section{Inna KRYNYTSKA ${ }^{1}$, Mariya MARUSHCHAK ${ }^{1 凶}$, Liliya ODNORIH $^{2}$, Olha MARTIANOVA $^{3}$}

${ }^{1}$ „I. Horbachevsky“ Ternopil State Medical University, Functional and Laboratory Diagnostics Department, Ternopil, Ukraine

2 „Danylo Halytsky“ Lviv National Medical University, Department of Medical Biology, Parasitology and Genetics, Lviv, Ukraine

3 „Danylo Halytsky“ Lviv National Medical University, Department of Clinical Laboratory Diagnostics on FPGH, Lviv, Ukraine

Received 15 July 2018, Accepted 07 Aug 2018

https://doi.org/10.31688/ABMU.2018.53.3.17

\section{Abstract}

Hepatopulmonary syndrome (HPS) is a severe complication seen in the advanced liver disease. It is characterized by the triad of abnormal arterial oxygenation caused by intrapulmonary vascular dilatations (IPVD) in the setting of advanced liver disease, portal hypertension, or congenital portosystemic shunts. Liver transplantation is the only curative option for HPS. Pulmonary vascular dilation and angiogenesis are two central pathogenic features that cause abnormal pulmonary gas exchange in experimental HPS, and thus might underlie HPS in humans. The vascular component includes diffuse or local dilation of the pulmonary capillaries, and less commonly includes pulmonary arteriovenous shunts. The mechanisms responsible for the vascular changes in HPS remain incompletely understood. Research into the underlying molecular mechanisms has mainly focused on the roles of nitric oxide (NO), carbon monoxide (CO), hydrogen sulfide $\left(\mathrm{H}_{2} \mathrm{~S}\right)$, ATP-sensitive $\mathrm{K}^{+}$channels $\left(\mathrm{K}_{\text {ATP }}\right.$ channels), endothelin-1 (ET-1), tumor necrosis factor-alpha $(\mathrm{TNF}-\alpha)$, etc. and is summarised below.

\section{RÉSUMÉ}

Le syndrome hépato-pulmonaire: médiateurs potentiels de la vasodilatation pulmonaire

Le syndrome hépato-pulmonaire (SPH) est une complication grave observée au préalable dans les cas de maladie du foie. Elle se caractérise par une triade d'oxygénation artérielle anormale causée par des dilatations vasculaires intrapulmonaires (IPVD) dans le cadre d'une maladie hépatique avancée, d'une hypertension portale ou de shunts porto-systémiques congénitaux. La transplantation hépatique est la seule option curative pour le SPH. La dilatation vasculaire pulmonaire et l'angiogenèse sont deux caractéristiques pathogènes centrales qui provoquent des échanges anormaux de gaz pulmonaire dans le SPH expérimental et pourraient donc être à la base du SHP chez l'homme. La composante vasculaire comprend une dilatation diffuse ou locale des capillaires pulmonaires et comprend moins fréquemment des shunts artérioveineux pulmonaires. Les mécanismes responsables des modifications vasculaires du SPH restent incomplètement 
Keywords: hepatopulmonary syndrome, vasodilation, mediators. compris. Les recherches sur les mécanismes moléculaires sous-jacents ont principalement porté sur les rôles de l'oxyde nitrique (NO), du monoxyde de carbone $(\mathrm{CO})$, du sulfure d'hydrogène $(\mathrm{H} 2 \mathrm{~S})$, des canaux $\mathrm{K}+$ sensibles à l'ATP (canaux KATP), de l'endothéline-1 (ET-1), le facteur de nécrose tumorale alpha $(\mathrm{TNF}-\alpha)$, etc. et sont resumees ci-dessous.

Mots-clés: syndrome hépato-pulmonaire, vasodilatation, médiateurs.

$\mathrm{P}$, calcitonin, glucagon, platelets activating factor, and others ${ }^{1}$.

Hepatopulmonary syndrome (HPS) is a severe complication seen in the advanced liver disease. HPS is characterized by the triad of abnormal arterial oxygenation caused by intrapulmonary vascular dilatations (IPVD) in the setting of advanced liver disease, portal hypertension, or congenital portosystemic shunts ${ }^{1}$. The occurrence of combined liver and lungs pathology was initially described by M. Fluckiger (Austria) in 1884 when he observed cyanosis and clubbed fingers in the young woman with liver cirrhosis due to the presence of syphilis ${ }^{2}$. Today the term "hepatopulmonary syndrome“ (HPS) describes deficiency of arterial oxygenation caused by dilatation of intrapulmonary vessels associated with liver disease $e^{3-5}$.

Non-specific clinical criteria combined with the lack of standardization of HPS diagnostic criteria can lead to diagnostic errors. It also explains the wide range of HPS frequency reported by authors. The occurrence of HPS in patients with cirrhosis ranges from 4 to $47 \%$ and in candidates for a liver transplant is from 15 to $20 \%{ }^{6}$. Moreover, researches have shown that in children with chronic liver disease HPS was diagnosed in 9 to $29 \%$ of cases?

Since the pathogenesis of HPS is not fully clarified, there is no effective pharmacological therapy and orthotopic liver transplant is the only successful treatment method $^{8}$.

Considering that splanchnic and systemic arterial vasodilatation is a hallmark of the progression of portal hypertension in patients with cirrhosis ${ }^{9}$ and the basis of HPS pathogenesis is the dilation of inner lung capillaries ${ }^{1}$, researches suggest that HPS is caused by the prolonged action of biologically active compounds on the blood vessels of the pulmonary circuit. A possible role in the emergence of resistant vasodilation has been suggested for many substances synthesized in the body. Potential mediators of HPS include nitrogen (II) oxide, endothelin B and endothelin-1, prostaglandins $\mathrm{E}_{1}$ and $\mathrm{I}_{2}$, tumor necrosis factor- $\alpha$, vasoactive intestinal polypeptide, substance

\section{Nitric oxide-mediated vasodilation}

Since nitrogen (II) oxide (NO) is recognized as one of the most powerful endogenous pulmonary vasodilators, it has been suggested as the most likely candidate not only for the hyperdynamic type of circulation in liver cirrhosis but also for $\mathrm{HPS}^{10}$. As a lipophilic molecule, NO easily diffuses through cell membranes into the neighbouring cells (e.g. from endothelial to myocytes of vessels) where cyclic guanosine monophosphate decreases the concentration of free calcium and activates myosin light chain kinase causing vessel dilatation ${ }^{11}$.

A series of experimental studies investigated NO quantities in the context of liver cirrhosis and HPS. Fallon et al. have emphasized the role of NO in experimental models of liver cirrhosis, where overexpression of eNOS by pulmonary vessels causes the increased production of endothelin-1 (ET-1) by cholangiocytes, resulting in increased expression of endothelin receptor type B to ET-1 at the level of pulmonary vessels, and increases synthesis of nitrogen (II) oxide ${ }^{12}$.

The level of NO in exhaled air was elevated in patients with HPS, and it returned to normal in 3 to 12 months after the liver transplant ${ }^{13}$. In a similar study, Degano et al. found that concentration of $\mathrm{NO}$ in exhaled air of patients with cirrhosis was three times higher than that in healthy person $s^{14}$. Krynytska and Marushchak found a significant increase in total NOS activity and concentration of $\mathrm{NO}^{2-}+\mathrm{NO}^{3-}$ in lung tissue of rats with HPS $^{15}$. Using flow cytometry, which allowed to differentiate the alveolar and bronchial origin of $\mathrm{NO}$, it was determined that the increased formation of $\mathrm{NO}$ mainly took place in the alveoli ${ }^{16}$. Notably, the production of nitrogen (II) oxide by alveoli can play an important role in haemodynamic disturbances and changes in gas exchange in patients with cirrhosis. Thus, a direct correlation between the alveolar production of $\mathrm{NO}$ and hyperdynamic type of circulation was established ${ }^{14}$. Moreover, 
overexpression of both inducible and constitutional isoforms of NO-synthase in alveolar macrophages and pulmonary endothelial cells was observed in rats with experimental liver cirrhosis ${ }^{17}$. While this pulmonary overexpression has not yet been found in patients with HPS, it probably occurs in most cases of HPS, at least in patients who have been successfully treated using inhibitors of nitrogen (II) oxide synthesis or its targets, so-called secondary messengers of cyclic guanosine monophosphate.

Several studies have successfully used the following therapeutic approaches in patients with HPS: either the intravenous introduction of methylene blue, which is the main inhibitor of $\mathrm{NO}$ molecular target, cyclic guanosine monophosphate or spraying with $\mathrm{NO}$ synthase inhibitor (N-nitro-L-arginine methyl ester $^{18-19}$.

However, further studies showed, that NO concentration does not affect hyperdynamic circulation and the severity of liver damage in cirrhosis patients. Thus, methylene blue has improved arterial oxygenation, but only temporarily, while L-NAME had no effect on gas exchange in many patients with HPS $^{20}$.

\section{Carbon monoxide and hydrogen sulfide}

In addition, other molecular mechanisms of nitric oxide-independent vasodilation are discussed in the literature, such as the enzymatic formation of carbon monoxide (CO) by increased expression of heam oxygenase-1 enzymatic formation of hydrogen sulfide $\left(\mathrm{H}_{2} \mathrm{~S}\right)$, and stimulation of calcium-activated potassium channels by endothelium-derived hyperpolarization factor ${ }^{21}$.

$\mathrm{CO}$ is a gaseous molecule that is synthesised in at least two distinct pathways. The first reaction is catalyzed by enzyme haem oxygenase. The secondary mechanism involves chemical reactions such as oxidation of certain organic molecules, including salts, alkyl radicals as well as autoxidation, and lipid peroxidation of cell membranes. The synthesis of cyclic guanosine monophosphate, which is induced by $\mathrm{CO}$ through activation of soluble guanylate cyclase, leads to blood vessels smooth muscle cells relaxation. There are three isoforms of haem oxygenase: $\mathrm{HO}-1$, HO-2, and HO-3. HO-1 is inducible, while HO-2 and HO-3 are stable in cells. HO-1, also known as heat shock protein, is mainly located in the liver, spleen, reticuloendothelial system and bone marrow ${ }^{21}$. HO-2 and $\mathrm{HO}-3$ can be found in various parts of the body; however, HO-2 is mainly detected in the brain, and blood vessels, while HO-3 is found in the spleen, liver, heart, kidneys, and brain. Reports indicate that in liver cirrhosis patients with HPS due to, the level of $\mathrm{HO}-1$ in pulmonary intravascular macrophages is increased and this is complemented by increased
$\mathrm{CO}$ production ${ }^{22}$. The existing reverse relationship between partial pressure of oxygen and carboxyhaemoglobin concentration in patients with HPS point to a potential impact of increased $\mathrm{CO}$ formation on the abnormal gas exchange. In addition, Van Landeghem et al have observed that zinc protoporphyrin, an HO-1 inhibitor, causes normalization of carboxyhaemoglobin levels in arterial blood, the decrease of pulmonary vasodilation and improvement of HPS symptoms ${ }^{23}$. These studies support the hypothesis that $\mathrm{HO}-1 / \mathrm{CO}$ system plays an important role in the pathogenesis of HPS.

Hydrogen sulfide $\left(\mathrm{H}_{2} \mathrm{~S}\right)$ is produced in all tissues, particularly in vascular endothelium ${ }^{24} . \mathrm{H}_{2} \mathrm{~S}$ synthesis from homocysteine is catalyzed only by cystathionine- $\beta$-synthase, whereas its synthesis from cysteine is catalyzed by several enzymes: cysteine aminotransferase, cystathionine- $\gamma-$ lyase and cystathionine- $\beta$-synthase. Hydrogen sulfide can also be synthesized by the reduction of thiosulfate by thiosulfate disulfide transferase. $\mathrm{H}_{2} \mathrm{~S}$ is involved in numerous reactions, including binding with $\mathrm{SH}$-groups of proteins and low molecular weight thiols, modifying their activity, interacting with sulfite anion, and forming thiosulfate. It can also be methylated by thiol methyltransferase, producing methanethiol. Additionally, hydrogen sulfide can produce nitrosothiols and nonenzymatically oxidate to sulfites and sulfates.

\section{ATP-sensitive $\mathbf{K}^{+}$channels}

Vascular tone is also regulated by ATP-sensitive $\mathrm{K}^{+}$channels ( $\mathrm{K}_{\text {ATP }}$ channels). They open in vascular smooth muscle cells, causing hyperpolarization and subsequent vasorelaxation ${ }^{22}$. The experiments with $\mathrm{K}_{\mathrm{ATP}}$ channel modulators in mesentery of rats with simulated secondary biliary cirrhosis have demonstrated that the channels are mostly open in dilated vessels ${ }^{25}$. In addition, $\mathrm{K}_{\text {ATP }}$ channels are the targets for $\mathrm{H}_{2} \mathrm{~S}$. The chemical identity of hyperpolarization factor has not yet been determined, however, some candidate compounds for its induced vasodilation action are proposed, including monovalent cations of potassium, metabolites of arachidonic acid, and hydrogen peroxide. The action of the hyperpolarization factor is the most prominent in small arteries and arterioles ${ }^{21}$.

A large number of studies on isolated perfused mesenteric arteries and aorta of rats with various models of portal hypertension showed that decreased vasoconstrictor response to $\alpha_{1}$-adrenoceptors agonists (phenylephrine, metoksamin, norepinephrine), angiotensin II and vasopressin persisted even after the removal of endothelium or pharmacological inhibition of endogenous $\mathrm{NO}$ production ${ }^{26}$. 
This hypocontractility can be due to malfunctioning vascular RhoA/Rho kinase signaling or disrupted response to angiotensin II as a result of increased expression of the receptor to $G$ protein-bound protein kinase 2 and protein $\beta$-arrestin 2 bound to angiotensin II receptor type $1^{27}$.

\section{Angiotensin II}

Another hypothesis stipulates that angiotensin II is a major etiological factor in HPS pathogenesis. According to this theory, HPS symptoms develop as a result of vascular dilatation associated with abnormal reactivity to angiotensin II (reduction of vasoconstrictor effect) and with simultaneous increase of $\mathrm{NO}$ concentration, a potent vasodilator.

In experiments on rats Castro et al. showed that the vasoconstrictor effect of angiotensin may be restored by inhibiting of $\mathrm{NO}^{28}$. Chang et al. observed in animal models that intravenous infusion of angiotensin II can partially restore disrupted constrictor ability of pulmonary vessels ${ }^{29}$. However, the current state of knowledge about the role of these factors is not sufficiently conclusive and requires further research.

Vasodilation is not the only mechanism responsible for the pathological process in HPS patients. In recent studies, inhalation treatment with L-NAME in patients with HPS resulted in a significant decrease of systemic and pulmonary vasodilation, however, their arterial hypoxemia has not improved ${ }^{30}$. Gomez et al. argue that arterial hypoxemia in patients with HPS is not strictly related to the existing vasodilator effect of $\mathrm{NO}^{20}$. It is likely, that vasodilation by itself does not cause more than 10-fold increase in the diameter of capillaries with little smooth muscle in HPS patients.

\section{Endothelin $\mathbf{- 1}$ and its receptors}

A lot of attention in the investigation of HPS pathogenic mechanisms is paid to endothelin-1 (ET-1), which is formed in the endothelium. It produces a large number of biologically active substances, serving as a paracrine organ. The main role of the endothelium is to maintain homeostasis by regulating the balance of opposite processes: vascular tone (vasoconstriction/vasodilatation), structural building of blood vessels (synthesis/inhibition of proliferation factors), haemostasis (synthesis/inhibition of fibrinolysis factors and platelets aggregation), and local inflammation (production of pro- and anti-inflammatory factors ${ }^{31}$. ET-1 acts by binding to receptors $\mathrm{ET}_{\mathrm{A}}, \mathrm{ET}_{\mathrm{B1}}$ and $\mathrm{ET}_{\mathrm{B} 2} \cdot \mathrm{ET}_{\mathrm{A}}$ and $\mathrm{ET}_{\mathrm{B} 2}$ receptors are localized in vascular smooth muscle. $\mathrm{ET}_{\mathrm{B1}}$ receptors are localized in endothelium ${ }^{32}$.

It may seem improbable that ET-1, a recognized vasoconstrictor, can cause vasodilation of the pulmonary microvascular bed. The local production of ET-1 in response to various stimuli is mostly abluminal and is associated with $\mathrm{ET}_{\mathrm{A}}$ receptors on vascular smooth muscle cells, causing contraction and vasoconstriction. A smaller amount of local peptide is released luminally (into the lumen of blood vessels) causing vasodilation due to increased eNOS activity and $\mathrm{NO}$ production by binding to $\mathrm{ET}_{\mathrm{B}}$ receptors $^{33}$.

Hyperproduction of ET-1 occurs in the liver of patients with HPS. Through the tight contact, ET-1 enters the circulatory system, binds to ET-receptors in the endothelial cells of the lung vessels, causing an increase in the expression and activity of eNOS, and vasodilation ${ }^{34}$. In addition, there is evidence that the introduction of $\mathrm{ET}_{\mathrm{B}}$ receptor selective antagonist to animals after ligation of the common bile duct causes a reduction in pulmonary endothelial eNOS and improvement of HPS symptoms ${ }^{35}$.

At the same time, modeling of experimental HPS in $\mathrm{ET}_{\mathrm{B}}$ receptor-deficient rats showed that level of ET-1 in plasma has not increased and HPS did not develop compared to the control group ${ }^{36}$.

Fallon described the increase in plasma levels of ET-1 within 2 weeks after ligation of the common bile duct in rats. This increase of ET-1 in plasma correlated with an increase in pulmonary eNOS, the magnitude of intrapulmonary vasodilation and gas exchange indicators ${ }^{12}$. The levels of NO and ET-1 were significantly elevated in plasma, liver and lung homogenate of rats with experimental models of HPS $^{37}$.

The increased hepatic production and concentration in the circulatory system of ET-1 were also detected in other experimental and human liver disorders. However, these concentrations were much lower compared to the outcomes of common bile duct ligation and they were detected only at advanced stages of the disease in the presence of significant hyperdynamic changes and ascites ${ }^{38}$.

\section{Angiogenesis}

Recent studies showed that angiogenesis is also an important factor in the pathogenesis of experimental HPS ${ }^{39}$. Physiological angiogenesis is a tissue response to hormonal stimulation or to external changes. Hypoxia is a major stimulus for angiogenesis, affecting metabolic pathways that are regulated by proteins such as hypoxia-inducible factor 1. This leads to overexpression of proangiogenic factors, including vascular endothelial growth factor family (VEGF) and fibroblasts growth factors.

VEGF-A is the most known among the vascular endothelial growth factors. In human, there are 4 isoforms of VEGF-A: VEGF-A121, VEGF-A165, 
VEGF-A189, VEGF-A206, arising from alternative splicing of mRNA. Isoforms have similar biological activity but significantly vary in bioavailability, which is determined by the size of molecules and is regulated at the genetic level.

VEGF-A acts by binding to appropriate tyrosine kinase receptors VEGFR1 and VEGFR2 and initiating phosphorylation processes. Hypoxia, in turn, increases the expression of both VEGFR1 and VEGFR2 receptors. As the action of proangiogenic factors dominates the action of antiangiogenic (thrombospondin-1), endothelial cells transform from the usual "sleeping" to the active state. This tipping point is called the initiation of angiogenesis." There are 4 main stages of angiogenesis ${ }^{40}$ :

1. Proteolytic destruction of the vascular basement membrane and intercellular matrix.

2. Migration of endothelial cells and their colonization of the extravascular space.

3. The proliferation of endothelial cells.

4. Formation of tubular structures, and of the new capillary net.

Urinary activator of plasminogen or urokinase is the main regulator of extracellular proteolysis, triggering the cascade of proteolytic reactions on the cell surface, which encourages formation and growth of blood vessels. In addition, proteases activate and release from the matrix the majority of angiogenic factors required for proliferation, migration, and invasion of cells. Finally, urokinase, interacting with its receptor and other proteins on the cell surface, modulates intracellular signaling, which ensures the directional movement of the cells ${ }^{41}$.

Thus, angiogenesis is induced when metabolic requirements exceed the existing capacity of vascular perfusion. This is an adaptive response to the relative lack of oxygen which increases angiogenic stimuli $^{40}$. Thus, the increase in the number of lung capillaries, increased pulmonary accumulation and activation of monocytes, Akt and eNos are all signaling pathways associated with angiogenesis. Introduction of pentoxifylline reduces capillary net and pulmonary accumulation of monocytes, thus regulating pulmonary angiogenic factors and improving the course of HPS ${ }^{39-40}$.

There was no observation of angiogenesis in thioacetamide induced non-biliary cirrhosis. In addition, monocytes accumulation was lower considerably and activation of Akt, eNos, and vascular endothelial growth factor $\mathrm{A}$ were not detected ${ }^{42}$.

Liver angiogenesis occurs through VEGFdependent pathways ${ }^{43}$. The expression of VEGF-A165, the subtype of VEGF-A was confirmed in pathological states, on experimental models of liver cirrhosis. Pulmonary intravascular accumulation of monocytes was low and VEGF-A expression was not significantly increased in cases of non-biliary cirrhosis induced by thioacetamide. This is in contrast to the effects of the common bile duct ligation in rats, where a significant accumulation of monocytes and overexpression of VEGF-A were observed. These effects decreased after the introduction of pentoxifylline, which is known to inhibit the adhesion of mononuclear cells to endothelial. It is argued that monocyte accumulation in the pulmonary microvascular bed can be explained by bacterial translocation and increased production of circulating TNF- $\alpha$. The positive impact of pentoxifylline may be due to its inhibition of TNF- $\alpha^{36}$.

However, other studies found that while the level of circulating TNF- $\alpha$ in liver cirrhosis induced by thioacetamide was significantly elevated, the accumulation of monocytes was minimal and HPS did not develop ${ }^{44}$.

\section{Intestinal endotoxemia}

Several authors examined a significant role of intestinal endotoxemia and bacterial translocation in the pathogenesis of HPS ${ }^{45-46}$. Liver damage makes it more difficult for the organ to filter blood from the portal vein, which leads to the appearance of portosystemic shunts and a decrease in the hepatic phagocytic capacity. As a result, the lung filtrates systemic blood to compensate for the decrease in hepatic phagocytosis, and the increase in the lung phagocytic activity results in macrophage accumulation in the pulmonary endothelium and increases cytokine and NO levels in the extracellular environment ${ }^{47}$.

Phagocytes also produce the superoxide anion radical, which oxides the plasmatic membrane and produces a substantial amount of reactive oxygen species (ROS) ${ }^{48-49}$. Many physiological functions are controlled by these molecules, including vascular tonus regulation. Tieppo et al. assessed the lipoperoxidation of pulmonary tissue following the experimental model of common bile duct ligation; using the techniques of thiobarbituric acid reactive substances and chemiluminescence, the authors identified a significant increase in the lipid peroxidation, which may be explained by the action of phagocytic cells when fighting against the process of bacterial translocation ${ }^{50}$.

Vallance and Moncada proposed that endotoxemia in liver cirrhosis is caused either directly by the movement of bacteria through the intestinal mucosa or indirectly through the cytokine cascade stimulates vascular endothelial iNOS, which increases the production of $\mathrm{NO}^{51}$.

There is evidence that in patients with liver cirrhosis the level of tumor necrosis factor- $\alpha$ increases, 
playing an important role in the accumulation of macrophages in the lumen of the pulmonary vessels. In turn, these macrophages encourage another NO-producing enzyme, inducible NO-synthase, thus likely causing pulmonary vasodilation ${ }^{12}$. However, other studies have found that while the level of circulating TNF- $\alpha$ was significantly increased in thioacetamide-induced liver cirrhosis, the accumulation of macrophages in the lumen of pulmonary vessels was minimal and HPS did not develop ${ }^{44}$. Studies suggest that neutralization of tumour necrosis factor- $\alpha$ improves the course of experimental HPS ${ }^{52}$.

Zhang et al showed a significant increase of endotoxin and TNF- $\alpha$ levels in plasma and increased number of Gram-negative microorganism colonies in rats with HPS, which suggests that intestinal endotoxemia is indeed implicated in the pathogenesis of experimental HPS ${ }^{46}$. TNF- $\alpha$ plays a role in the damage of the intestinal barrier that results in intestinal endotoxemia and bacteremia. Subsequently, intestinal endotoxemia can cause intrapulmonary vasodilation and hypoxia. Hypoxemia can exacerbate intestinal barrier damage due to the release of a number of cytokines (including TNF- $\alpha$ ). Thus, a «vicious circle» develops in which hypoxemia and impaired barrier function of the intestinal mucosa intensifiy each other ${ }^{46}$.

Therewith bile acids have a bacteriostatic effect on the intestinal flora. In liver cirrhosis their secretion is reduced, causing excessive bacterial growth. As a result of microorganism activity in the small intestine, the concentration of unconjugated bile acids increases. It damages mucosa epithelium causing inactivation of glycoproteins in the apical membrane of brush border microvilli and increases mucosa epithelium permeability ${ }^{53}$.

\section{Conclusions}

HPS is a severe complication seen in advanced liver disease. It is characterized by the triad of abnormal arterial oxygenation caused by intrapulmonary vascular dilatations in the setting of advanced liver disease, portal hypertension, or congenital portosystemic shunts. Pulmonary vascular dilation and angiogenesis are two central pathogenic features that cause abnormal pulmonary gas exchange in experimental HPS, and thus might underlie HPS in humans. The vascular component includes diffuse or local dilation of the pulmonary capillaries, and less commonly includes pulmonary arteriovenous shunts. The mechanisms responsible for the vascular changes in HPS remain incompletely understood, thus, liver transplantation seems to be the only effective treatment for HPS.
Future research should address the genetic polymorphisms associated with the hepatopulmonary syndrome, circulating factors emanating from the hepatic veins that may affect the pulmonary vascular tone and angiogenic factors.

\section{Compliance with Ethics Requirements:}

„The authors declare no conflict of interest regarding this article"

"No funding for this study"

\section{References}

1. Krowka MJ, Fallon MB, Kawut SM, et al. International Liver Transplant Society Practice Guidelines: Diagnosis and Management of Hepatopulmonary Syndrome and Portopulmonary Hypertension. Transplantation 2016, 100:1440-1452.

2. Fluckiger M. Vorkommen von trommelschagel formigen fingerendphalangen ohne chronische veranderungen an der lungen oder am herzen. Wien Med Wochenschr 1884, 34:1457-1461.

3. Amin Z, Amin HZ, Tedyanto NM. Hepatopulmonary syndrome: a brief review. Romanian Journal of Internal Medicine 2016, 54(2):93-97.

4. Krynytska I, Marushchak M, Mikolenko A, et al. Differential diagnosis of hepatopulmonary syndrome (HPS): portopulmonary hypertension (PPH) and hereditary hemorrhagic telangiectasia (HHT). Bosnian Journal of Basic Medical Sciences 2017, 17(4): 276-85.

5. Abrahamovych O, Abrahamovych M, Tolopko S, Ferko M. Character and frequency of the variations of co- and polymorbid syntropic extrahepatic lesions and their dependence on the hepatopulmonary syndrome severity degree in cirrhotic patients. Georgian Medical News 2016, 11(260):34-41.

6. Gorgy AI, Jonassaint NL, Stanley SE, et al. Hepatopulmonary syndrome is a frequent cause of dyspnea in the short telomere disorders. Chest 2015, 148:1019.

7. Borkar VV, Poddar U, Kapoor A, Srivastava A, Yachha SK. Hepatopulmonary Syndrome in children: a comparative study of non-cirrhotic vs. cirrhotic portal hypertension. Liver International 2015, 35(6):1665-1672.

8. Cosarderelioglu C, Cosar AM, Gurakar M, Dagher NN, Gurakar A. Hepatopulmonary syndrome and liver transplantation: a recent review of the literature. Journal of Clinical and Translational Hepatology 2016, 4(1):47.

9. Diaconescu D, Pantea Stoian A, Socea LI, et al. Hepatorenal syndrome: a review Arch Balk Med Union 2018, 53(2):239-245.

10. Dinh-Xuan A T, Naeije R. The hepatopulmonary syndrome: NO way out? European Respiratory Journal 2004, 23(5):661-662.

11. Fafula RV, Iefremova UP, Onufrovych OK, et al. Alterations in arginase-NO-synthase system of spermatozoa in human subjects with different fertility potential. J Med Biochem 2018, 37(2):134-140.

12. Fallon MB. Mechanisms of pulmonary vascular complications of liver disease: hepatopulmonary syndrome. Journal of Clinical Gastroenterology 2005, 39(4):S138-142.

13. Hamamoto J, Toba S, Hirosako S, Nakamura K, Fujii K, Kohrogi H. A case of hepatopulmonary syndrome with 
elevated exhaled nitric oxide. Nihon Kokyuki Gakkai Zasshi 2010, 48(5):379-384.

14. Degano B, Mittaine M, Hervé P, et al. Nitric oxide production by the alveolar compartment of the lungs in cirrhotic patients. European Respiratory Journal 2009, 34(1):138-44.

15. Krynytska I, Marushchak M. The indices of nitrogen (II) oxide system in case of experimental hepatopulmonary syndrome. The Ukrainian Biochemical Journal 2018, 90(5): http:// ua.ukrbiochemjournal.org/magarchive.

16. Delclaux C, Mahut B, Zerah-Lancner F, et al. Increased nitric oxide output from alveolar origin during liver cirrhosis versus bronchial source during asthma. American Journal of Respiratory and Critical Care Medicine 2002, 165(3):332-337.

17. Zhang J, Ling Y, Luo B, et al. Analysis of pulmonary heme oxygenase-1 and nitric oxide synthase alterations in experimental hepatopulmonary syndrome. Gastroenterology 2003, 125:1441-1451.

18. Aksu B, Umit H, Kanter M, et al. Effects of methylene blue in reducing cholestatic oxidative stress and hepatic damage after bile-duct ligation in rats. Acta Histochemica 2010, 112(3):259-269.

19. Brussino L, Bucca C, Morello M, Scappaticci E, Mauro M, Rolla G. Effect on dyspnoea and hypoxaemia of inhaled N G-nitro-L-arginine methyl ester in hepatopulmonary syndrome. The Lancet 2003, 362(9377):43-44.

20. Gómez FP, Barberà JA, Roca J, Burgos F, Gistau C, Rodríguez-Roisin R. Effects of nebulized NG-nitro-L-arginine methyl ester in patients with hepatopulmonary syndrome. Hepatology 2006, 43(5):1084-1091.

21. Garbuzenko DV. The pathophysiological mechanisms and new areas of treatment of portal hypertension in liver cirrhosis. Clin Perspectives of Gastroenterol, Gepatol 2010, (6):11-20.

22. Van Landeghem L, Laleman W, Vander EI, et al. Carbon monoxide produced by intrasinusoidally located haem-oxygenase-1 regulates the vascular tone in cirrhotic rat liver. Liver Int 2009, 29(5):650-660.

23. Arguedas MR, Drake BB, Kapoor A, Fallon MB. Carboxyhemoglobin levels in cirrhotic patients with and without hepatopulmonary syndrome. Gastroenterology 2005, 128(2):328-333.

24. Félétou M. The endothelium, Part I: Multiple functions of the endothelial cells-focus on endothelium-derived vasoactive mediators. In Colloquium Series on Integrated Systems Physiology: From Molecule to Function 2011, 3(4):1-306.

25. Atucha NM, Ortíz MC, Fortepiani LA, Nadal FJ, Martínez-Prieto C, García-Estañ J. Mesenteric hyporesponsiveness in cirrhotic rats with ascites: role of cGMP and $\mathrm{K}^{+}$ channels. Clinical Science 2000, 99(5):455-460.

26. Hennenberg M, Trebicka J, Sauerbruch T, Heller J. Mechanisms of extrahepatic vasodilation in portal hypertension. Gut 2008, 57(9):1300-1314.

27. Hennenberg M, Biecker E, Trebicka J, et al. Defective RhoA/Rho-kinase signaling contributes to vascular hypocontractility and vasodilatation in cirrhotic rats. Gastroenterology 2006, 130(2):838-854.

28. Castro A, Jiménez W, Clária J, et al. Impaired responsiveness to angiotensin II in experimental cirrhosis: role of nitric oxide. Hepatology 1993, 18(2):367-372.

29. Chang SW, Ohara N. Pulmonary circulatory dysfunction in rats with biliary cirrhosis. Am Rev Respir Dis 1992, 148:798-805.

30. Ho V. Current concepts in the management of hepatopulmonary syndrome. Vascular Health and Risk Management 2008, 4(5):1035-1041.
31. Félétou M. Endothelium-derived vasoactive factors and hypertension: possible roles in pathogenesis and as treatment targets. Curr Hypertens Rep. 2010, 12(4): 267-275.

32. Reichetzeder C, Tsuprykov O, Hocher B. Endothelin receptor antagonists in clinical research - Lessons learned from preclinical and clinical kidney studies. Life Sciences 2014, 118(2):141-148

33. Zhang ZJ, Chang-Qing Y. Progress in investigating the pathogenesis of hepatopulmonary syndrome. Hepatobiliary Pancreat Dis Int 2010, 9(4):355-360.

34. Vercelino R, Tieppo J, Forgiarini Junior LA, Dias AS, Marroni CA, Marroni NP. Experimental models for assessment of pulmonary alterations in hepatopulmonary syndrome. J Bras Pneumol 2008, 34(7):453-460.

35. Ling Y, Zhang J, Luo B, et al. The role of endothelin-1 and the endothelin $B$ receptor in the pathogenesis of hepatopulmonary syndrome in the rat. Hepatology 2004, 39(6):1593-1602

36. Zhang J, Ling Y, Tang L, Luo B, Pollock DM, Fallon MB. Attenuation of experimental hepatopulmonary syndrome in endothelin B receptor-deficient rats. Am J Physiol Gastrointest Liver Physiol 2009, 296(4):G704-G708.

37. Yan Y, Bao XQ, Wang Y. Roles of vascular mediators in the pathogenesis of hepatopulmonary syndrome in rats. Shijie Huaren Xiaohua Zazhi 2008, 16:1053-1058.

38. Luo B, Abrams GA, Fallon MB. Endothelin-1 in the rat bile duct ligation model of hepatopulmonary syndrome: correlation with pulmonary dysfunction. J Hepatology 1998, 29(4):571-578.

39. Zhang J, Luo B, Tang L, et al. Pulmonary angiogenesis in a rat model of hepatopulmonary syndrome. Gastroenterology 2009, 136(3):1070-1080.

40. Sprindzhuk MV. Angiogenesis. Annals of Restorative Medicine 2010, (5):15-20.

41. Tsokolaeva ZI. Stimulation of angiogenesis in ischemic myocardium and skeletal muscles by transient transgenic expression of urokinase [disertation], Moscow 2006.

42. Fallon MB, Abrams GA, McGrath JW, Hou Z, Luo B. Common bile duct ligation in the rat: a model of intrapulmonary vasodilatation and hepatopulmonary syndrome. American Journal of Physiology-Gastrointestinal and Liver Physiology 1997, 272(4):G779-784.

43. Bosch J. Vascular deterioration in cirrhosis: the big picture. Journal of Clinical Gastroenterology 2007, 41:S247-253.

44. Luo B, Liu L, Tang L, Zhang J, Ling Y, Fallon MB. Et-1 and TNF-alpha in HPS: analysis in prehepatic portal hypertension and biliary and nonbiliary cirrhosis in rats. Am J Physiol Gastrointest Liver Physiol 2004, 286(2): G294-G303.

45. Seo YS, Shah VH. The role of gut-liver axis in the pathogenesis of liver cirrhosis and portal hypertension. Clin Mol Hepatol 2012, 18(4):337-346.

46. Zhang HY, Han DW, Su AR, et al. Intestinal endotoxemia plays a central role in development of hepatopulmonary syndrome in a cirrhotic rat model induced by multiple pathogenic factors. World J Gastroenterol 2007, 13(47):6385-6395.

47. Dal Bosco A, Schedler FB, Colares JR, Dias AS, Marroni NP. Hepatopulmonary syndrome: oxidative stress and physical exercise. EMJ 2017, 2(4):69-75.

48. Demikhova N, Sukhonos V, Vynnychenko L, Psareva $\mathrm{V}$, Prikhodko O. Activation of lipid peroxidation in patients with renal hypertension. Georgian Med News 2013, (215):51-55.

49. Marushchak M, Krynytska I, Petrenko N, Klishch I. The determination of correlation linkages between level of reactive oxygen species, contents of neutrophiles and blood 
gas composition in experimental acute lung injury Georgian Medical News 2016, (253):98-103.

50. Tieppo J. Common bile duct ligation as a model of hepatopulmonary syndrome and oxidative stress. Arq Gastroenterol 2005, 42(4):244-248.

51. Vallance P, Moncada S. Hypothesis: induction of nitric oxide synthase in the vasculature underlies the hyperdynamic circulation of cirrhosis. Lancet 1991, 337:776-778.
52. Liu L, Liu N, Zhao Z, et al. TNF- $\alpha$ neutralization improves experimental hepatopulmonary syndrome in rats. Liver International 2012, 32(6):1018-1026.

53. Garbuzenko DV. The role of intestine microflora in the development of portal hypertension in hepatic cirrhosis. Clin Medicine 2007, (8):15-19. 